\title{
Measuring Consumer Preferences for Video Content Provision via Cord-Cutting Behavior
}

\author{
Jeffrey Prince and Shane Greenstein*
}

October 2013

\begin{abstract}
The television industry is undergoing a generational shift in structure; however, many demandside determinants are still not well understood. We model how consumers choose video content provision among: over-the-air (OTA), paid subscription to cable or satellite, and online streaming (also known as over-the-top, or OTT). We apply our model to a U.S. dataset encompassing both the digital switchover for OTA and the emergence of OTT, along with a recession, and use it to analyze cord-cutting behavior (i.e., dropping of cable/satellite subscriptions). We find high levels of cord cutting during this time, and evidence that it became relatively more prevalent among low-income and younger households - suggesting this group responded to changes in OTA and streaming options. We find little evidence of households weighing relative content offerings/quality when choosing their means of video provision during the timespan of our data. This last finding has important ramifications for strategic interaction between content providers.
\end{abstract}

\footnotetext{
* Indiana University, Department of Business Economics and Public Policy, Kelley School of Business, and Northwestern University, Department of Management and Strategy, Kellogg School of Management. We thank Fernando Laguarda and seminar participants at the $41^{\text {st }}$ Telecommunications Policy Research Conference and the Kelley School Business Economics Brown Bag for helpful comments. We are responsible for all errors.
} 


\section{Introduction}

Television is the single biggest use of leisure time (Wallsten, 2013), and all participants widely acknowledge that it is undergoing a generational shift in structure as video content provision is converging. The demand-side determinants are not well understood, but the recent U.S. boon in digital television offers an opportunity to cast light on those determinants. Specifically, over the years 2008 and 2009, the telecommunications landscape experienced two major changes: 1) the digital switchover for over-the-air (OTA) television and 2) a mass increase in network content available for online streaming (primarily in the form of Hulu and Netflix), often labeled as over-the-top (OTT). At the same time, the United States experienced the brunt of a very large recession. During this period, we also observe a significant reduction of pay television subscriptions. Any or all of the aforementioned changes could have generated the observed change in pay television subscriptions. Further, the way in which households responded to these changes has important implications concerning consumer preferences and the competitive landscape that may emerge.

In this paper, we measure key determinants of consumers' choices across these video provision options by analyzing cord cutting behavior (i.e, the dropping of subscription cable/satellite television services). In doing so, we determine: which subgroups of consumers are most likely to cord cut, whether there is a convergence to the general population among the group that cord cuts, and the extent to which relative content offerings/quality impacts households' choices over content provision. To accomplish this last task, we employ a wellknown choice model, allowing households to choose between OTA via digital antenna, paid subscription to cable or satellite, and OTT. To our knowledge, this is the first paper to attempt to measure consumer preferences across video provision methods that include online streaming.

Understanding how consumers choose across these options can provide key insights into the evolution of the telecommunications landscape. In particular, we can track whether demographic indicators of cord cutting behavior are converging or diverging, and thus determine whether or not cord cutting is heading toward the main stream. Further, knowing the role that content offerings play in consumers' choice of content provision sheds light on how competition across provision methods is evolving. More concretely, if relative content is weighed heavily, then expansion of content availability on OTT could be a key driver of future cord cutting; if not, 
then other changes to OTA and OTT are likely important toward these options becoming more viable substitutes for a paid subscription to cable or satellite.

To perform our analyses, we employ a rich dataset provided by Forrester Research. The data consist of independent cross sectional surveys of tens of thousands of American households on an annual basis. These surveys collect information on technological purchases and preferences, as well as a wide range of demographic information (income, education, etc.) and location. We focus our analysis on the last few years of the survey in our possession (20072009), when the aforementioned shifts in the video content provision market occurred in the United States.

Our econometric analysis focuses on cord cutting behavior, and how it was influenced by changes in the telecommunications landscape. We begin by developing a simple choice model over video content provider options. A key feature of this model is that it allows utility for each option to depend on individual-level content preferences and relative content availability across options. This feature allows us to identify whether consumers notably weigh relative content offerings (which changed with the emergence of OTT) and/or relative content quality (which changed with the digital switchover). We estimate this model utilizing methods suitable for repeated cross-sectional data (as in Prince and Greenstein, 2013).

Our data indicate a significant increase in cord-cutting between the years of 2008 and 2009. We do not find evidence that this shift can be explained by wealth shocks; however, we do find evidence that households already prone to cord cut (i.e., young and low income) likely became even more prone to this behavior during this time. This latter finding is suggestive of a response by this group to the change in OTA and emergence of OTT. Lastly, we find no evidence that relative content availability/quality is a notable driver of cord cutting behavior. Specifically, households with pre-existing preferences for content that was either added to (in the case of OTT), or improved for (in the case of OTA), alternative provider options did not demonstrate a notable difference in their propensity to cord cut. This finding suggests changes along these dimensions were not major factors behind the cord cutting we observed.

Our results indicate a divergence in demographic characteristics driving cord cutting behavior. That is, the standard cord cutter was becoming less similar to the average U.S. household. Further, they show that increased content offerings (OTT) / quality (OTA) by alternatives to paid cable/satellite subscriptions alone are not key drivers toward these options 
becoming stronger substitutes. For example, with regard to OTT, they suggest that other changes such as an alternative delivery method or original content development will likely need to occur for this provision option to become a more viable competitor to cable/satellite.

An important caveat to these findings is the relatively early stage during which we observe these changes to OTA and OTT. However, the time period between 2008 and 2009 is also a highly attractive time to analyze given the great turmoil in the telecommunications markets at that time. It would take several years of data during alternative time periods to match the (potential) identification power of the data during this turbulent year. Nevertheless, we recognize this analysis occurs while the telecommunications markets are in a state of flux, and view these findings as valuable first steps toward understanding the direction it is headed and key underlying determinants of competition.

The remainder of the paper is organized as follows. In Section 2, we detail the key changes to the video content provision market that occurred between 2008 and 2009. In Section 3, we describe our data. In Section 4 we lay out our theoretical model, and in Section 5 we detail our econometric specification and estimation method. In Section 6, we discuss our results, and Section 7 concludes.

\section{Three Events Impacting the On-Demand Video Market}

In this section, we discuss three events that may have significantly impacted the landscape of the on-demand video market. Each event has measurable implications in out data, particularly with regard to cord-cutting behavior, as we discuss in greater detail in Section 4 .

\subsection{The Great Recession}

In late 2007, a significant global recession began that affected many countries around the world, including the United States. The recession became especially pronounced in the Fall of 2008. The ramifications of this economic downturn were felt in many industries, including telecommunications. To the extent that paid subscriptions for cable and satellite (henceforth "pay TV") are normal goods, we should expect an increase in cord-cutting behavior (i.e., dropping of cable/satellite paid subscriptions) corresponding to the drop in income and wealth 
due to the recession. Hence, this macroeconomic event may be a key driver of cord cutting we observe in our data (described below).

Even for households not hit hard by the Recession, the change it brought to consumer confidence and outlook can also have an impact on consumers' decision-making for household purchases. Paid television subscriptions can cost $\$ 1,000$ per year or more, so it is reasonable to believe that households making such a purchase may have taken pause to reconsider it during this time. Consequently, the shift in financial means and outlook during the Recession is a key factor in helping us identify drivers behind the provision choices households make.

\subsection{The U.S. Digital Switchover}

The Digital Switchover is the process by which analog television broadcasting is discontinued and replaced by digital television. Beginning in 2006 in the Netherlands, this process has taken place (and is scheduled to take place) in many countries spanning the subsequent twenty years. In the United States, the switch by television stations initially was scheduled to take place in February of 2009. It largely did at the beginning of 2009, and following the DTV Delay Act, was mandated to occur by June 12, 2009.

By using digital technology, broadcasters could provide higher quality reception compared to analog (e.g., it is less prone to ghosting of images), and they could offer highdefinition television service. Broadly speaking, the switchover allowed broadcasters to offer content of higher quality along several dimensions, among other things. This improvement in a potential substitute for subscription television may have contributed to an increase in cord cutting, particularly if the quality of OTA content is generally considered when making a provider decision. ${ }^{1}$

\subsection{The Emergence of Over-the-Top from Network Television}

From 2003 to 2008 the average household allocated an average of eight minutes a day to using the internet for leisure. By 2011 that had increased by 50\%, to over twelve minutes a day.

\footnotetext{
${ }^{1}$ Most households experienced an increase in quality, and in spite of fears of considerable variance in the quality of the digital signal. This smooth transition occurred in spite of a great deal of fear-mongering, as well as a four month delay in the full switchover. See, e.g., http://www.fcc.gov/digital-television, and for an example of the fear mongering, see http://usgovinfo.about.com/od/consumerawareness/a/dtvmaps.htm (accessed October, 2013).
} 
Many commentators forecast that the increase in time on the Internet would come at the expense of television viewing, the activity to which households devote more than half their leisure time (Wallsten, 2013, page 10). ${ }^{2}$ Many suppliers prepared for this transition.

The ability to stream network television content over a broadband connection largely began due to Netflix and Hulu. Netflix began as a DVD-by-mail company that eventually offered streaming content over the Internet as well. It first allowed for streaming of movies in mid-2007, but did not have notable television content available for streaming until its partnership with Starz Entertainment in late 2008. It also added deals with CBS, NBC and Disney to stream their content shortly thereafter. A subscription for streaming content is typically around $\$ 10$ or less per month in the U.S. as of this writing, and this price has been relatively stable since 2008.

Hulu is a website that offers OTT content. It was available to the public in March of 2008. Unlike Netflix, Hulu began with a stronger focus on streaming television (rather than movie) content, partnering with several television networks early on (detailed more in Section 3). Similar to Netflix, Hulu currently offers a subscription version of its service at less than $\$ 10$ per month; however, prior to 2010, all of Hulu's content was available for free.

With Hulu and Netflix firmly in place as OTT content providers by 2009, television subscribers (through cable or satellite) possessed another ubiquitous alternative for television content via a broadband connection. Since a broadband connection was necessary to receive OTT content, the cost of this option could be substantial ( $\$ 500+$ per year); however, for the approximately $60 \%$ of U.S. households already with broadband by this time, the added cost of using OTT was quite small. The emergence of this new potential substitute for subscription television may also have contributed to an increase in cord cutting behavior. To the extent that households weigh the content offerings of OTT when choosing a content provider, OTT could become an even stronger contributor to cord cutting behavior if OTT content increases.

\footnotetext{
${ }^{2}$ As of 2011 Wallsten (2013) finds no strong evidence of the reallocation of time from television to the internet.
} 


\section{Data}

The data for this project come from multiple sources. The first is Forrester Research, Inc. Each year, Forrester privately collects cross-sections consisting of thousands of household surveys, known as their "technographics" surveys. The surveys contain detailed information on households' technology purchases, activities, and preferences, along with a wide range of demographic measures. Our analysis focused on the three most recent waves, which surround the events described above and have similar survey structure: 2007-2009. Although Forrester attempts to produce a survey that samples the population across different locations and economic circumstances, it also makes no pretense that its sample precisely represents the U.S. population. In total, this demographic information serves three purposes: 1) as controls, 2) to identify comparable subgroups across years when constructing a pseudo-panel (as described in Section 5), and 3) to determine differential shifts in behavior across demographic subgroups. The demographic information we utilized includes DMA, ${ }^{3}$ education, income, household size, and age.

Beyond demographics, the questions most pertinent to our analysis are those concerning: whether the household subscribes to cable or satellite, whether the household has broadband Internet, and the television channels the respondent consistently watches. Regarding televisionwatching behavior, the surveys ask respondents "Which of the following TV channels do you regularly watch on TV?” followed by an exhaustive list of popular television channel options (over 55). This component of the survey is particularly valuable to our analysis, as it allows us to establish content preferences, and determine how responses to changes in the telecommunications market depend on these preferences.

We provide summary statistics for our key variables in Table 1 below. Among these statistics, we include proportions of households who had all four binary (Yes or No) combinations of (satellite or cable) subscription TV and broadband. Particularly interesting statistics are the large change between 2008 and 2009 in the proportion of households with broadband Internet and no TV, along with the large drop in overall TV subscribers. While these data are not necessarily a representative sample of the U.S. population (e.g., they tend to over-

\footnotetext{
${ }^{3}$ A DMA is a designated market area. DMAs generally coincide with sizeable cities in the United States.
} 
sample high income households), these results are highly suggestive of a notable change in consumer behavior between 2008 and 2009, especially given there is no evidence of any change between 2007 and $2008^{4}$. The last set of variables in Table 1 are indicator variables as to whether the respondent claimed to watch a given television channel regularly. The particular channels we include are those with the highest rate of consumption in the prior year (approximately 20\% or higher) along with two that are seemingly particular to Netflix (Starz and Disney). In addition, we created a variable called "Broadcast" which equals one if the household watched at least two broadcast channels (and zero otherwise) and a variable called Nonbroadcast which equals one if the household watched at least two non-broadcast channels among the list we consider for OTT (and zero otherwise). We use these last two variables to conduct further robustness tests, described in Section 6.

\section{[Table 1 about here]}

A key limitation of our data from Forrester is that it is not in the form of a panel, but rather repeated cross sections. As we detail below, much of our analysis focuses on (changes in) household behavior over time, which provided us many challenges for our econometric approach. In Section 5, we outline how we deal with these challenges using repeated crosssectional data.

Our remaining data contain information about the television network offerings of Hulu and Netflix. For Hulu, we use the Internet archive (also known as the Way Back Machine), which provides website captures of the web page listing all networks associated with Hulu. In particular, we utilized a late-December (12/26/09) capture of the website www.hulu.com/partners. Among the channels included in the Forrester survey, Hulu is affliated with the following channels at that point in time: ABC, A\&E Network, Bravo, CNBC, Comedy Central, Current TV, DIY Network, E!, Food Network, Fox, Fox Business, Fox News Channel, Fox Sports Net, FX, HGTV, MSNBC, MyNetworkTV, National Geographic, NBC, Oxygen, PBS, Showtime, Starz, and USA.

\footnotetext{
${ }^{4}$ Note that, even when we weight results to be representative along observable demographics, this shift is still evident.
} 
For Netflix, unfortunately it is not possible to use the Internet archive in the same way as with Hulu, since there is no single page listing network affiliations with Netflix of which we are aware. Therefore, we instead used archived public press releases to establish which television networks were affiliated with Netflix by late 2009. From this search ${ }^{5}$, we were able to establish that Starz, CBS, and Disney were all affiliated with Netflix by this time.

\section{A Simple Model of Video Media Demand}

In this section, we provide a basic theoretical model of demand for video content provision. Using this model, we demonstrate how we can identify the set of characteristics for a given product that consumers consider when making a choice. We then build upon the ideas presented here when constructing our econometric model below.

Our theoretical framework follows the random utility approach of, e.g., Nevo (2000). Each period, consumers choose one video content provider among the following four choices: subscription television (cable or satellite), over the air (OTA) television, online streaming (OTT), and no provider. The utility for individual $i$ from choosing video provision option $j$ at time $t$ is as follows:

(1) $U_{i j t}=\alpha_{i}\left(y_{i t}-p_{j t}\right)+\left(1-\delta_{j}\right)\left[\overrightarrow{\text { Content }_{j t}} * \overrightarrow{\beta_{l}}+\overrightarrow{\text { Content }_{j t}} * \overrightarrow{\text { Quality }_{j t}} * \overrightarrow{\gamma_{l}}\right]+\eta_{j}+$ $\varepsilon_{i j t}$

where $y_{i t}$ is income for individual $i$ at time $t, p_{j t}$ is price for option $j$ at time $t$, Content is a vector of content available for option $j$, Quality is a vector of quality levels for each content component for option $j, \eta_{j}$ is unobserved, time-invariant utility for option $j$ (constant across individuals), and $\varepsilon_{i j t}$ is unobserved utility for option $j$ at time $t$ for individual $i$. Also, $\alpha_{i}, \beta_{i}$ and $\gamma_{i}$ are individuallevel coefficients, representing heterogeneous preferences for option characteristics across individuals. Lastly, $\delta_{j}$ represents product-level discounting of utility from content and content quality, where $\delta_{\text {subscription }}$ has been normalized to equal 0 . Note that this last parameter can

\footnotetext{
${ }^{5}$ Sites utilized include: http://bits.blogs.nytimes.com/2008/10/01/starz-gives-netflix-fans-a-reason-to-stream/? _r=0, http://paidcontent.org/2008/09/23/419-netflix-makes-deals-with-cbs-disney-on-tv-shows/.
} 
capture differences across products in how individuals derive utility from that product's content and content quality.

Given this utility formulation and the standard Type I extremum distributional assumption for the idiosyncratic error, the probability that individual $i$ chooses option $j$ at time $t$ is $^{6}$ :

$$
\begin{aligned}
& \text { (2) } \mathrm{P}_{i j t}\left(\overrightarrow{p_{t}}, \overrightarrow{\text { Content }} t, \overrightarrow{\text { Quality }_{t}} ; \alpha_{i}, \overrightarrow{\beta_{l}}, \overrightarrow{\gamma_{l}}, \overrightarrow{\delta_{J}}\right)= \\
& \frac{\exp \left(-\alpha_{i} p_{j t}+\left(1-\delta_{j}\right)\left[\overrightarrow{\text { Content }_{j t}} * \overrightarrow{\beta_{l}}+\overrightarrow{\text { Content }_{j t}} * \overrightarrow{\text { Quallty }_{j t}} * \overrightarrow{\gamma_{l}}\right]+\eta_{j}\right)}{\sum_{k=1}^{4} \exp \left(-\alpha_{i} p_{k t}+\left(1-\delta_{k}\right)\left[\overrightarrow{\text { Content }_{k t}} * \overrightarrow{\beta_{l}}+\overrightarrow{\text { Content }_{k t}} * \overrightarrow{\text { Qualt }_{k t}} * \vec{\gamma}_{i}\right]+\eta_{k}\right)}
\end{aligned}
$$

A primary aim of our empirics is to determine whether consumers take into account content availability and/or quality when considering whether to use OTA or OTT instead of subscription television. One could attempt to determine this by directly estimating the $\delta$ parameters for OTA and OTT and using standard maximum likelihood methods. If they are measured to be positive and significant, this would indicate that consumers consider these features notably less (or not at all) compared to pay television when making their choices.

Unfortunately, as we indicate in our data section, the above approach is not viable since we do not completely observe the choices made by consumers. Instead, we only know for certain whether or not they chose to purchase subscription television. While this is a limitation, we also have measures that provide direct information about consumer content preferences (i.e., provide information about $\beta_{i}$ ).

Consider now the probability of choosing pay television by person $i$ at time $t$. For expositional purposes, assume that $\gamma_{i}=0$. Then, this probability is:

$$
\text { (3) } \mathrm{P}_{\text {isubt }}\left(\overrightarrow{p_{t}}, \overrightarrow{\text { Content }}, \overrightarrow{\text { Quality }_{t}} ; \alpha_{i}, \overrightarrow{\beta_{l}}, \overrightarrow{\delta_{J}}\right)=\frac{\exp \left(-\alpha_{i} p_{\text {subt }}+\overrightarrow{\text { Content }_{\text {subt }}} * \overrightarrow{\beta_{l}}+\eta_{\text {sub }}\right)}{\sum_{k=1}^{4} \exp \left(-\alpha_{i} p_{k t}+\left(1-\delta_{k}\right)\left({\text { Content } k_{k t}}^{\prime}+\overrightarrow{\beta_{l}}\right)+\eta_{k}\right)}
$$

Suppose now that $\beta_{i} \in[0, B]$, where $\mathrm{B}>0$. Then, it follows immediately that:

\footnotetext{
${ }^{6}$ Note that income drops out of the expression since it is common in all terms.
} 


$$
\begin{aligned}
& \text { (4) } \frac{\partial}{\text { dontent }_{\text {OTT }}}\left(\mathrm{P}_{\text {isubt }}\left(\overrightarrow{p_{t}}, \overrightarrow{\text { Content }_{t}}, \overrightarrow{\text { Quality }_{t}} ; \alpha_{i}, B, \overrightarrow{\delta_{J}}\right)-\right. \\
& \left.\mathrm{P}_{\text {isubt }}\left(\overrightarrow{p_{t}}, \overrightarrow{\text { Content }} t, \overrightarrow{\text { Quality }_{t}} ; \alpha_{i}, 0, \overrightarrow{\delta_{J}}\right)\right)<0 \text { iff } \delta_{\text {OTT }}<1
\end{aligned}
$$

In words, this means that: the difference in likelihood of choosing subscription television between an individual that gains utility from content and one that doesn't is decreasing in OTT content availability if and only if OTT content is considered. We note here that it is also true that $\mathrm{P}_{\text {isubt }}\left(\overrightarrow{p_{t}}, \overrightarrow{\text { Content }_{t}}, \overrightarrow{\text { Quality }_{t}} ; \alpha_{i}, B, \overrightarrow{\delta_{J}}\right)$ is decreasing in content availability for OTT if and only if $\delta_{\text {Отт }}$ is less than 1 . However, this observation leads to a weaker empirical test, since it does not allow us to control for changes in other factors when content is added.

If we allow for $\gamma_{i} \neq 0$ but assume that $\beta_{i}=0$ implies $\gamma_{i}=0$, the above claim still holds. If we further assume that $\beta_{\mathrm{i}}>0$ implies $\gamma_{\mathrm{i}}>0$, we can make a similar claim with regard to content quality for both OTT and (more pertinent to our empirics) OTA. In words, these assumptions mean that an individual can't care about the quality of certain content, but not care about that content; and, if an individual cares about content, that individual cares to some extent about its quality. The similar claim for OTA is as follows:

$$
\begin{aligned}
& \text { (5) } \frac{\partial}{\text { dquality }_{\text {OTA }}}\left(\mathrm{P}_{\text {isubt }}\left(\overrightarrow{p_{t}}, \overrightarrow{\text { Content }} t, \overrightarrow{\text { Quallty }_{t}} ; \alpha_{i}, B, \overrightarrow{\delta_{J}}\right)-\right. \\
& \left.\mathrm{P}_{\text {isubt }}\left(\overrightarrow{p_{t}}, \overrightarrow{\text { Content }} t, \overrightarrow{\text { Quallty }_{t}} ; \alpha_{i}, 0, \overrightarrow{\delta_{J}}\right)\right)<0 \text { iff } \delta_{\text {OTA }}<1
\end{aligned}
$$

In words, this means that: the difference in likelihood of choosing subscription television between an individual that gains utility from content and one that doesn't is decreasing in OTA quality if and only if OTA content is considered.

The above insights lead to two clear empirical tests.

1. Suppose two individuals are identical, but for preference for particular content (e.g., Comedy Central). Then if we observe the difference in their likelihood of purchasing subscription television decline when this content is added to the OTT option, it implies OTT content is considered when making their media choice; otherwise, it is not.

2. Suppose two individuals are identical, but for preference for particular content (e.g., NBC). If we observe the difference in their likelihood of purchasing subscription 
television decline when NBC quality is improved for OTA, this implies OTA content quality is considered when making their media choice; otherwise, it is not.

Our ability to conduct these two tests relies on there being proper variation in the data and utilization of a proper econometric model. As described in Section 2, our data contain shifts in OTT content availability and OTA content quality. And, in Section 5 below, we design our econometric model to conduct these tests for our full population, and for relevant demographic subgroups. Further, it is easy to expand our model to allow for preferences to depend on demographic characteristics (typically labeled as a matrix, X), which include, e.g., income and age among others.

We conclude by noting that the choice we model above is a simplified one. For example, to choose OTT also requires a subscription to broadband services. Further, an individual could conceivably choose more than one of these options simultaneously (e.g., subscription and OTT, OTT and OTA, etc.). However, to the extent that claims \#1 and \#2 still hold in such extensions (which is likely to be the case barring some extreme forms of complementarity), our econometric approach described in Section 5 will still be appropriate for our purposes.

\section{Econometric Model}

The econometric model we analyze uses a binary variable indicating subscription to cable or satellite television in period $t$ (2009 or 2008) as the dependent variable. The most basic version of this model includes explanatory variables consisting of household demographic characteristics, and allows for differential effects across the two years. The model looks as follows:

(6) $T V_{i t}=\beta_{1}+\beta_{2} T V_{i t-1}+\beta_{3} \mathrm{I}(\mathrm{t}=2009)+\overrightarrow{\alpha_{1}} \overrightarrow{\mathrm{X}_{1}}+\beta_{4} \mathrm{I}(\mathrm{t}=2009) \mathrm{TV} \mathrm{V}_{\mathrm{it}-1}+\overrightarrow{\alpha_{2}} \overrightarrow{X_{l}} \mathrm{I}(t=$ 2009) $+\varepsilon_{i t}$

Here, $X_{i}$ is a set of time-invariant household characteristics for household $i$ (e.g., education, location, family size, and income) and I(2009) is an indicator variable for the second wave of data. Using this model, we can get some basic notions as to which demographic groups are most 
prone to subscribe to pay cable/satellite television, and any changes in their relative propensity to do so in our second wave of data. Any differences we find are not directly indicative differing propensities to cord cut, but given the high penetration rate in 2008 (82\%) and the large drop into 2009 (change of 5\%), they are highly suggestive.

Next, we present the extended version of our model, which allows us to determine the role of content preferences in this decision process and test the two hypotheses put forth at the end of Section 4. We present it below:

(7) $T V_{i t}=\beta_{1}+\vec{\alpha}_{1} \overrightarrow{X_{l}}+\overrightarrow{\alpha_{2}} \overrightarrow{X_{l}} I(t=2009)+\beta_{2} T V_{i t-1}+\beta_{3} \mathrm{I}(\mathrm{t}=2009)+\beta_{4} \mathrm{I}(\mathrm{t}=$

$$
\begin{aligned}
& \text { 2009) } \mathrm{TV}_{\mathrm{it}-1}+\beta_{5} \text { Content }_{i 1 t-1}+\cdots+\beta_{k+4} \text { Content }_{i k t-1}+ \\
& \beta_{k+5} \mathrm{I}(\mathrm{t}=2009) \text { Content }_{i 1 t-1}+\cdots+\beta_{2 k+4} \mathrm{I}(\mathrm{t}=2009) \text { Content }_{i k t-1}+\varepsilon_{i t}
\end{aligned}
$$

Here, Content ${ }_{i j t-1}$ is a binary variable indicating whether household $i$ viewed television content $j$ at time $t-1$.

The identification strategy for this model is as follows. Content for non-broadcast channels can only be observed if the household subscribed to cable/satellite television, since these observations are made before OTT network content was available. Therefore, the nonbroadcast content variable coefficients are only identified holding $T V_{t-1}$ fixed and equal to 1. This means that these variables are only helping to predict the dropping of subscription service. For broadcast channels (e.g., NBC, ABC), this does not apply since they can be observed even if the household has not subscribed to cable/satellite. Therefore, these variables technically are helping to predict net changes in cable/satellite TV subscriptions; however, as the digital switchover enhances the value of OTA, any changes we observe in the relationship between broadcast content preferences and subscription TV preferences are almost certainly due to changes in cord cutting as well.

In general, we may worry that these Content variables are endogenous. That is, content choices last period may be correlated with unobservables influencing a household's decision to subscribe to cable/satellite television this period. It is also an obvious concern that $T V_{i t-1}$ may be endogenous as well. In addition, for a given household observed at time $t$, we cannot observe that household's choices at time $t$-1. However, using methods in Prince and Greenstein (2013), we can use group averages in place of the lagged variables, and with some basic assumptions 
(most importantly, no "group effects," explained below), we not only have a suitable proxy for these variables, but one that does not suffer from endogeneity. Of course, we must choose how to design these groups based on time-invariant household features.

Since a full discussion of the identification strategy using a pseudo panel is in Section 5.2 of Prince and Greenstein (2013), we provide a brief summary here. This approach follows a long line of research using repeated cross sections (e.g., Deaton, 1985; Moffitt, 1993; Collado, 1997; McKenzie, 2004; Verbeek and Vella, 2005). Here, we group the households according to location (DMA), education, size, age, and income (using the categories in Table 1, except for DMA). Then, for each household at time $t$, we replace variables that are not observed for that household at time $t-1$ with the average for households we do observe at time $t-1$ that are in the same group. For example, in equation (5), $T V_{i t-1}$ would be replaced with $\overline{T V}_{g t-1}$, where $g$ is the group of which household $i$ is a member. Taking this approach both addresses the problem of missing information, and alleviates some endogeneity concerns. The primary concern with regard to endogeneity that remains is whether unobservables harbor "group effects," i.e., timeinvariant unobservables that vary at the group level. While we cannot completely rule out the possibility of such effects, our fine level of grouping (allowing for a great number of demographic controls) helps alleviate their presence.

Using the above model, we can identify the effects of prior content choice for both years. The structural shift in OTA and OTT television (through newly available streaming content via OTT and the digital switchover in OTA) suggests that prior content choice will have a differing impact on subscription cord cutting behavior in 2009 as compared to 2008. Specifically, we would expect that, if these changes were impactful via their content offerings, then the coefficients for Content available via OTA and/or OTT should decline between 2008 and 2009 (in line with Tests \#1 and \#2 at the end of Section 4). This is because these two changes had differing implications as to the availability of content through alternative means. For example, the digital switchover primarily impacted the quality of network television, and local stations, available over the air; in contrast, the increase in streaming capability allowed for access to a subset of non-broadcast channels, such as Comedy Central more easily over the Internet. 


\section{Results}

Our results for variants of equation (6) are in Table 2 below. In column (1), we see that subscription to cable or satellite is strongly related to income and age (increasing in both). For education and household size, we see a non-monotonic relationship, where likelihood of subscription is greatest for the middle levels of each variable. In columns (2) and (3), we allow for the effects of demographic variables to change across 2008 and 2009. Here, we see that age, income, and education became even stronger predictors of cable/satellite subscription by 2009. In column (3), we add a control for the change in wealth experienced by the household. This variable is the household's stated wealth in time $t$ minus the average stated wealth for households in the same group at time $\mathrm{t}-1$. Using this control, we find no evidence of subscription decisions being strongly tied to changes in household wealth experienced during this time (we see a notable decline in wealth between 2007 and 2008, as expected). However, given the relatively low response for this particular variable in the data, we are cautious to draw any strong conclusions about the impact of wealth changes.

\section{[Table 2 about here]}

In Table 3, we present our results for variants of equation (7). The objective is to determine whether consumers of particular content (indicative of preference for that content) altered their purchasing patterns for cable/satellite subscription service in different ways than other consumers. The results in column (1) suggest this is not the case. As noted in Section 3, the particular channels we include are those with the highest rate of consumption in the prior year (approximately 20\% or higher) along with two that are seemingly particular to Netflix (Starz and Disney). If consumers are responding to the content offerings and quality of OTT and OTA, we should expect the coefficients for the interaction terms (channel interacted with 2009) to be negative. However, we see no such pattern.

\section{[Table 3 about here]}

In column (2) of Table 3, we try even harder to find this pattern, by allowing for a differential effect for those particularly at high risk of dropping subscription television, i.e., the young and poor. Consequently, we define a dummy variable "High risk" to be one if the household has income less than $\$ 75,000$ and age less than 45 . Using this variable, we can zero 
in on the subgroup that may be most likely to exhibit any response to changes in content offerings since they are the most prone to drop service anyway. The results in column (2) corroborate our original findings; even the "high risk" households indicate no particular response to changes in content for OTA and OTT.

A possible shortcoming in the above analyses is their focus on single channels for preferences. In Table 4, we use our dichotomous variables Broadcast and Non-broadcast, which are designed to capture relatively high preference for broadcast channels (at least two) or nonbroadcast channels offered by OTT (at least two non-broadcast channels included in Table 3). These variables allow us to focus on households that have a relatively high preference for content offered by OTT or improved by OTA. If there is a response to content offerings by these alternatives to cable/satellite, we might expect it to be particularly prevalent among this group. The results in Table 4 corroborate our findings in Table 3. In column (1), we again see no notable effects for the interactions of these terms with 2009, indicating no notable change in their propensity to subscribe to cable/satellite relative to other households. In column (2), we again allow for an interaction with being high risk. Here, there is some mild evidence of high risk, broadcast watchers becoming more prone to cord cut, but the estimate is not statistically significant.

\section{[Table 4 about here]}

It is natural to ask whether there is enough power in our data to find an effect if it exists. However, rather than engage in the complicated task of choosing what would be a "notable" effect and testing for power across many coefficients, we note the following. First, our sample size is quite large and capable of identifying effects for our demographic variables and $\mathrm{TV}_{\mathrm{t}-1}$. Second, our estimates for content do not exhibit any pattern suggestive of a broad effect - many estimates for content interacted with 2009 are positive, and very few are more negative than 0.01 (only CBS in column (1)). Last, our results focusing on "high risk" households also show no indication of a broad pattern. The channel with a particularly large amount of content and an audience squarely within this group is Comedy Central; however, we see no evidence of the high risk Comedy Central watchers cord cutting more in 2009. 
We conclude this section by noting that the lack of a content effect in our data may be due to the timing of our data - perhaps it is too early to tell. We acknowledge this as a caveat for

our findings. However, given the stickiness of telecom purchases (e.g., see Prince and Greenstein, 2013), these data are particularly well suited toward finding an effect if it exists due to the broad shock to the market over 2008-2009. At the very least, these results show that early on, OTA and OTT were not viably competing with cable and satellite on content. Whether that has continued to be the case, particularly for an evolving competitor in OTT, is a question for future research.

\section{Conclusions}

In this paper, we presented and estimated a model designed to identify how OTA and OTT compete with traditional cable and satellite subscription television. Our results indicate that the young and less wealthy are at the highest risk of cord cutting, and became even more likely to cord cut relative to other demographic groups over time. We also find that improvements in content quality and offerings for OTA and OTT respectively did not notably alter how these alternative content provision methods compete with cable and satellite. This is even the case when we focus on high risk cord cutters.

These findings have several implications. First, the digital switchover appears not to have had a notable effect on cable or satellite; hence this major government initiative does not appear to have had any of the feared detrimental effects on subscriptions. Second, there appears to be a divergence in the types of households prone to cord cut, at least during the time of our analysis - cord cutting was not moving in the direction of the "main stream." Lastly, at least during the early stages of development, OTT does not appear to compete with cable and satellite in any meaningful way in terms of content offerings. To the extent that this remains the case, this limits OTT as a serious threat to cable and satellite. However, changes since 2009 including original content offerings and promotions by OTT providers (e.g., Netflix) may prove an effective strategic response to this initial indifference to OTT content offerings. 


\section{References}

Abel, J. 2002. Entry into Regulated Monopoly Markets: The Development of a Competitive Fringe in the Local Telephone Industry. Journal of Law and Economics 95: 298-316.

Bulow, J., Geanakoplos, J., and P. Klemperer. 1985. Multimarket Oligopoly: Strategic Substitutes and Complements. Journal of Political Economy 93: 488-511.

Caves, K. 2011. Quantifying Price-driven Wireless Substitution in Telephony.

Telecommunications Policy 35: 984-998.

Chipty, T. 2001. Vertical Integration, Market Foreclosure, and Consumer Welfare in the Cable Television Industry. American Economic Review 91: 428-453.

Collado, M. 1997. Estimating dynamic models from time series of independent cross-sections. Journal of Econometrics 82:37-62.

Cuesta, J., H. Nopo, and G. Pizzolitto. 2011. Using pseudo-panels to measure income mobility in Latin America. Review of Income and Wealth 57:224-246.

Deaton, A. 1985. Panel data from time series of cross-sections. Journal of Econometrics 30:109126.

Faulhaber, G. 2003. Policy-induced Competition: The Telecommunications Experiments. Information Economics and Policy 15: 73-97.

Goolsbee, A. and Petrin, A. 2004. The Consumer Gains from Direct Broadcast Satellites and the Competition with Cable TV. Econometrica 72(2): 351-381.

Hart, J. 2010. The Transition to Digital Television in the United States: The Endgame. International Journal of Digital Television 1: 7-29.

Lehr, W. and Chapin, J. 2010. On the Convergence of Wired and Wireless Access Network Architectures. Information Economics and Policy 22: 33-41.

Loomis, D. and Swann, C. 2005. Intermodal Competition in Local Telecommunications Markets. Information Economics and Policy 17: 97-113.

McKenzie, D. 2004. Asymptotic theory for heterogeneous dynamic pseudo-panels. Journal of Econometrics 120:235-262.

Moffitt, R. 1993. Identification and estimation of dynamic models with a time series of repeated cross-sections. Journal of Econometrics 59:99-123.

Paul, S. 2011. Digital Video Distribution in Broadband, Television, Mobile and Converged Networks: Trends, Challenges and Solutions. Wiley John \& Sons, Inc. 
Prince, J. and Greenstein, S. 2013. Does Service Bundling Reduce Churn? forthcoming in the Journal of Economics and Management Strategy.

Sung, N., Lee, Y.-H. 2002. Substitution between Mobile and Fixed Telephones in Korea. Review of Industrial Organization 20: 367-374.

Verbeek, M., and F. Vella. 2005. Estimating dynamic models from repeated cross-sections. Journal of Econometrics 127:83-102.

Vogelsang, I. 2010. The Relationship between Mobile and Fixed-line Communications: A Survey. Information Economics and Policy 22:4-17.

Wallsten, S. 2013. What are we not Doing When we are Online? NBER Working paper 13001. http://www.nber.org/chapters/c13001.pdf.

Wirth, M. 2005. Issues in Media Convergence. In Handbook of Media Management and Economics, eds. Albarran, A., Chan-Olmsted, S., and Wirth, M., Lawrence Erlbaum Associates.

Zimmerman, P. 2008. Strategic Incentives under Vertical Integration: The Case of Wirelineaffiliated Wireless Carriers and Intermodal Competition in the U.S. Journal of Regulatory Economics 34: 282-298. 


\section{Tables}

Table 1

Summary Statistics

\begin{tabular}{|c|c|c|c|c|c|c|c|c|c|}
\hline Variable & \multicolumn{3}{|c|}{2007} & \multicolumn{3}{|c|}{2008} & \multicolumn{3}{|c|}{2009} \\
\hline & Mean & Std. Dev. & Count & Mean & Std. Dev. & Count & Mean & Std. Dev. & Count \\
\hline Television & 0.806345 & 0.395166 & 53,936 & 0.823 & 0.382 & 47,698 & 0.774 & 0.418 & 36,194 \\
\hline $\begin{array}{c}\text { Television \& } \\
\text { Broadband }\end{array}$ & 0.4945 & 0.5000 & 53,936 & 0.5399 & 0.4984 & 47,698 & 0.5325 & 0.4989 & 36,194 \\
\hline $\begin{array}{c}\text { Television \& } \\
\text { No } \\
\text { Broadband }\end{array}$ & 0.3084 & 0.4618 & 53,936 & 0.2785 & 0.4483 & 47,698 & 0.2167 & 0.4120 & 36,194 \\
\hline $\begin{array}{l}\text { Broadband \& } \\
\text { No Television } \\
\end{array}$ & 0.0664 & 0.2490 & 53,936 & 0.0650 & 0.2384 & 47,698 & 0.1175 & 0.3220 & 36,194 \\
\hline $\begin{array}{c}\text { No } \\
\text { Broadband \& } \\
\text { No Television }\end{array}$ & 0.1307 & 0.3371 & 53,936 & 0.1165 & 0.3208 & 47,698 & 0.1334 & 0.3400 & 36,194 \\
\hline $\begin{array}{c}\text { Income < } \\
\$ 25 \mathrm{~K} \\
\end{array}$ & 0.198309 & 0.39873 & 53,936 & 0.204055 & 0.403013 & 47,698 & 0.197408 & 0.398049 & 36,194 \\
\hline $\begin{array}{c}\text { Income \$25- } \\
50 \mathrm{~K} \\
\end{array}$ & 0.300004 & 0.458263 & 53,936 & 0.277328 & 0.447685 & 47,698 & 0.260955 & 0.439161 & 36,194 \\
\hline $\begin{array}{c}\text { Income } \$ 50- \\
75 \mathrm{~K}\end{array}$ & 0.184496 & 0.387892 & 53,936 & 0.179483 & 0.383761 & 47,698 & 0.164641 & 0.370861 & 36,194 \\
\hline $\begin{array}{c}\text { Income } \$ 75- \\
100 \mathrm{~K}\end{array}$ & 0.161117 & 0.367642 & 53,936 & 0.159147 & 0.365817 & 47,698 & 0.174891 & 0.379879 & 36,194 \\
\hline $\begin{array}{l}\text { Income } \\
\$ 100 K+\end{array}$ & 0.156074 & 0.362929 & 53,936 & 0.179987 & 0.38418 & 47,698 & 0.202105 & 0.401576 & 36,194 \\
\hline $\begin{array}{c}\text { Less than } \\
\text { H.S. }\end{array}$ & 0.061091 & 0.239499 & 53,936 & 0.063126 & 0.243193 & 47,698 & 0.062027 & 0.241208 & 36,194 \\
\hline $\begin{array}{c}\text { High School } \\
\text { diploma }\end{array}$ & 0.251706 & 0.433997 & 53,936 & 0.260451 & 0.438885 & 47,698 & 0.249378 & 0.432659 & 36,194 \\
\hline Some College & 0.341497 & 0.474216 & 53,936 & 0.336597 & 0.472551 & 47,698 & 0.330055 & 0.470239 & 36,194 \\
\hline $\begin{array}{l}\text { College } \\
\text { diploma }\end{array}$ & 0.21075 & 0.407845 & 53,936 & 0.209191 & 0.406735 & 47,698 & 0.221307 & 0.415133 & 36,194 \\
\hline $\begin{array}{l}\text { More than } \\
\text { college } \\
\text { diploma } \\
\end{array}$ & 0.134956 & 0.34168 & 53,936 & 0.130634 & 0.337004 & 47,698 & 0.137233 & 0.344098 & 36,194 \\
\hline $\mathrm{HH}$ size $=1$ & 0.163935 & 0.37022 & 53,936 & 0.171307 & 0.376781 & 47,698 & 0.161988 & 0.368445 & 36,194 \\
\hline HH size $=2$ & 0.365359 & 0.481535 & 53,936 & 0.368925 & 0.482519 & 47,698 & 0.343565 & 0.474905 & 36,194 \\
\hline $\mathrm{HH}$ size $=3$ & 0.20541 & 0.404005 & 53,936 & 0.203363 & 0.402504 & 47,698 & 0.20263 & 0.401965 & 36,194 \\
\hline HH size $=4$ & 0.167476 & 0.373404 & 53,936 & 0.161537 & 0.36803 & 47,698 & 0.177074 & 0.381736 & 36,194 \\
\hline HH size $=5+$ & 0.09782 & 0.297073 & 53,936 & 0.094868 & 0.293035 & 47,698 & 0.114743 & 0.318716 & 36,194 \\
\hline Age $<25$ & 0.090218 & 0.286497 & 53,936 & 0.082268 & 0.274775 & 47,698 & 0.093634 & 0.291323 & 36,194 \\
\hline Age $25-34$ & 0.156778 & 0.363595 & 53,936 & 0.134974 & 0.3417 & 47,698 & 0.160773 & 0.367326 & 36,194 \\
\hline Age $35-44$ & 0.190355 & 0.392585 & 53,936 & 0.17898 & 0.38334 & 47,698 & 0.196607 & 0.397438 & 36,194 \\
\hline Age 45-54 & 0.219149 & 0.413673 & 53,936 & 0.213699 & 0.409921 & 47,698 & 0.19622 & 0.397143 & 36,194 \\
\hline Age 55-64 & 0.170851 & 0.376382 & 53,936 & 0.189652 & 0.392029 & 47,698 & 0.174559 & 0.379595 & 36,194 \\
\hline
\end{tabular}




\begin{tabular}{|c|c|c|c|c|c|c|c|c|c|}
\hline Age 65+ & 0.172649 & 0.377947 & 53,936 & 0.200428 & 0.400325 & 47,698 & 0.178206 & 0.382692 & 36,194 \\
\hline $\begin{array}{c}\text { TV Shows } \\
\text { online }\end{array}$ & 0.086 & 0.280 & 48,675 & 0.117 & 0.321 & 41,593 & 0.185 & 0.388 & 36,428 \\
\hline $\begin{array}{c}\text { Wealth } \\
\text { change (\$mil) }\end{array}$ & & & & -0.02273 & 1.520 & 19,146 & 0.03642 & 1.3660 & 15,227 \\
\hline ABC & 0.702258 & 0.45727 & 53,936 & 0.626211 & 0.483814 & 47,698 & & & \\
\hline CBS & 0.656741 & 0.474801 & 53,936 & 0.631683 & 0.482353 & 47,698 & & & \\
\hline NBC & 0.643503 & 0.478969 & 53,936 & 0.628391 & 0.48324 & 47,698 & & & \\
\hline Fox & 0.523343 & 0.49946 & 53,936 & 0.513963 & 0.49981 & 47,698 & & & \\
\hline A\&E & 0.251279 & 0.433753 & 53,936 & 0.310034 & 0.462512 & 47,698 & & & \\
\hline Food & 0.267002 & 0.442397 & 53,936 & 0.283911 & 0.450899 & 47,698 & & & \\
\hline PBS & 0.27681 & 0.447426 & 53,936 & 0.300558 & 0.458505 & 47,698 & & & \\
\hline ComCentral & 0.195825 & 0.396838 & 53,936 & 0.201623 & 0.401216 & 47,698 & & & \\
\hline USA & 0.31111 & 0.462952 & 53,936 & 0.326156 & 0.46881 & 47,698 & & & \\
\hline Starz & 0.089143 & 0.284952 & 53,936 & 0.110424 & 0.313421 & 47,698 & & & \\
\hline Disney & 0.147638 & 0.354744 & 53,936 & 0.167932 & 0.373809 & 47,698 & & & \\
\hline Broadcast & 0.725731 & 0.446150 & 53,936 & 0.694809 & 0.460493 & 47,698 & & & \\
\hline $\begin{array}{c}\text { Non- } \\
\text { broadcast }\end{array}$ & 0.417068 & 0.493079 & 53,936 & 0.463604 & 0.498679 & 47,698 & & & \\
\hline
\end{tabular}


Table 2

Basic Cord Cutting Analysis ${ }^{7}$

\begin{tabular}{|c|c|c|c|}
\hline Covariate & (1) & (2) & (3) \\
\hline & Estimate & Estimate & Estimate \\
\hline \multirow[t]{2}{*}{ TV avg } & $0.163 * *$ & $0.168 * *$ & $0.172 * *$ \\
\hline & 0.009 & 0.009 & 0.011 \\
\hline \multirow[t]{2}{*}{2009} & $-0.093 * *$ & $-0.174 * *$ & $-0.180 * *$ \\
\hline & 0.012 & 0.026 & 0.034 \\
\hline \multirow[t]{2}{*}{ TV avg * 2009} & $0.055 * *$ & $0.044 * *$ & $0.055^{* *}$ \\
\hline & 0.013 & 0.014 & 0.018 \\
\hline \multirow[t]{2}{*}{ Income $\$ 25-50 \mathrm{~K}$} & $0.079 * *$ & $0.075^{* *}$ & $0.080 * *$ \\
\hline & 0.006 & 0.007 & 0.009 \\
\hline \multirow[t]{2}{*}{ Income $\$ 50-75 \mathrm{~K}$} & $0.114^{* *}$ & $0.110^{* *}$ & $0.116^{* *}$ \\
\hline & 0.006 & 0.008 & 0.01 \\
\hline \multirow[t]{2}{*}{ Income $\$ 75-100 \mathrm{~K}$} & $0.136 * *$ & $0.124^{* *}$ & $0.135 * *$ \\
\hline & 0.006 & 0.008 & 0.01 \\
\hline \multirow[t]{2}{*}{ Income $\$ 100 \mathrm{~K}+$} & $0.157 * *$ & $0.150 * *$ & $0.153^{* *}$ \\
\hline & 0.006 & 0.008 & 0.01 \\
\hline \multirow[t]{2}{*}{ High School diploma } & $0.043^{* *}$ & $0.029 *$ & $0.033^{*}$ \\
\hline & 0.009 & 0.012 & 0.015 \\
\hline \multirow[t]{2}{*}{ Some College } & $0.046 * *$ & 0.023 & 0.03 \\
\hline & 0.009 & 0.012 & 0.015 \\
\hline \multirow[t]{2}{*}{ College diploma } & $0.039 * *$ & 0.019 & 0.026 \\
\hline & 0.01 & 0.013 & 0.016 \\
\hline \multirow[t]{2}{*}{ More than college diploma } & $0.029 * *$ & 0.004 & 0.007 \\
\hline & 0.01 & 0.013 & 0.017 \\
\hline \multirow[t]{2}{*}{ HH size $=2$} & $0.058 * *$ & $0.055^{* *}$ & $0.062 * *$ \\
\hline & 0.005 & 0.007 & 0.009 \\
\hline \multirow[t]{2}{*}{ HH size $=3$} & $0.061^{* *}$ & $0.062 * *$ & $0.067 * *$ \\
\hline & 0.006 & 0.008 & 0.01 \\
\hline \multirow{2}{*}{ HH size $=4$} & $0.051 * *$ & $0.047 * *$ & $0.060 * *$ \\
\hline & 0.006 & 0.008 & 0.011 \\
\hline \multirow[t]{2}{*}{ HH size $=5+$} & 0.015 & 0.006 & 0.02 \\
\hline & 0.008 & 0.01 & 0.013 \\
\hline \multirow[t]{2}{*}{ Age 25-34 } & $0.069 * *$ & $0.055^{* *}$ & 0.023 \\
\hline & 0.008 & 0.011 & 0.015 \\
\hline \multirow[t]{2}{*}{ Age 35-44 } & $0.074 * *$ & $0.067 * *$ & $0.037 *$ \\
\hline & 0.008 & 0.01 & 0.014 \\
\hline \multirow[t]{2}{*}{ Age 45-54 } & $0.075 * *$ & $0.061^{* *}$ & $0.039 *$ \\
\hline & 0.008 & 0.01 & 0.014 \\
\hline \multirow[t]{2}{*}{ Age 55-64 } & $0.086^{* *}$ & $0.070^{* *}$ & $0.041^{*}$ \\
\hline & 0.008 & 0.011 & 0.015 \\
\hline \multirow[t]{2}{*}{ Age 65+ } & $0.066^{* *}$ & $0.052 * *$ & $0.032 *$ \\
\hline & 0.008 & 0.011 & 0.015 \\
\hline
\end{tabular}

\footnotetext{
${ }^{7}$ All regressions include fixed effects for DMA and a constant term. Standard errors below each point estimate are robust to arbitrary heteroskedasticity. * is significant at $10 \%, * *$ is significant at $5 \%$, and $* * *$ is significant at $1 \%$. Note that column (3) has fewer observations due to non-response to the wealth question; this drives the seemingly significantly higher R-squared.
} 


\begin{tabular}{|c|c|c|c|}
\hline Income $\$ 25-50 \mathrm{~K} * 2009$ & & 0.008 & 0.01 \\
\hline & & 0.011 & 0.014 \\
\hline \multirow[t]{2}{*}{ Income $\$ 50-75 \mathrm{~K} * 2009$} & & 0.007 & 0.019 \\
\hline & & 0.012 & 0.016 \\
\hline \multirow[t]{2}{*}{ Income $\$ 75-100 \mathrm{~K} * 2009$} & & $0.027^{*}$ & 0.021 \\
\hline & & 0.012 & 0.016 \\
\hline \multirow[t]{2}{*}{ Income $\$ 100 \mathrm{~K}+* 2009$} & & 0.017 & 0.019 \\
\hline & & 0.012 & 0.016 \\
\hline \multirow[t]{2}{*}{ High School diploma*2009 } & & 0.031 & 0.032 \\
\hline & & 0.019 & 0.024 \\
\hline \multirow[t]{2}{*}{ Some College*2009 } & & $0.052 * *$ & 0.046 \\
\hline & & 0.019 & 0.024 \\
\hline \multirow[t]{2}{*}{ College diploma*2009 } & & $0.044^{*}$ & 0.04 \\
\hline & & 0.02 & 0.025 \\
\hline \multirow[t]{2}{*}{$\begin{array}{l}\text { More than college } \\
\text { diploma*2009 }\end{array}$} & & $0.057 * *$ & $0.061^{*}$ \\
\hline & & 0.021 & 0.026 \\
\hline \multirow[t]{2}{*}{ HH size $=2 * 2009$} & & 0.007 & -0.008 \\
\hline & & 0.011 & 0.014 \\
\hline \multirow[t]{2}{*}{ HH size $=3 * 2009$} & & -0.001 & -0.01 \\
\hline & & 0.012 & 0.015 \\
\hline \multirow[t]{2}{*}{ HH size $=4 * 2009$} & & 0.01 & -0.008 \\
\hline & & 0.013 & 0.017 \\
\hline \multirow[t]{2}{*}{ HH size $=5+* 2009$} & & 0.02 & 0.003 \\
\hline & & 0.016 & 0.02 \\
\hline \multirow[t]{2}{*}{ Age $25-34 * 2009$} & & 0.032 & $0.048^{*}$ \\
\hline & & 0.017 & 0.023 \\
\hline \multirow[t]{2}{*}{ Age $35-44 * 2009$} & & 0.017 & 0.025 \\
\hline & & 0.016 & 0.022 \\
\hline \multirow[t]{2}{*}{ Age 45-54*2009 } & & $0.032 *$ & 0.039 \\
\hline & & 0.016 & 0.022 \\
\hline \multirow[t]{2}{*}{ Age 55-64*2009 } & & $0.038 *$ & $0.055^{*}$ \\
\hline & & 0.017 & 0.022 \\
\hline \multirow[t]{2}{*}{ Age $65+* 2009$} & & $0.034 *$ & 0.045 \\
\hline & & 0.017 & 0.023 \\
\hline \multirow[t]{2}{*}{ ln(wealth change) } & & & -0.0017 \\
\hline & & & 0.0013 \\
\hline R-squared & 0.074 & 0.074 & 0.083 \\
\hline $\mathrm{N}$ & 59,738 & 59,738 & 34,373 \\
\hline
\end{tabular}


Table 3

The Role of Content in Cord Cutting ${ }^{8}$

\begin{tabular}{|c|c|c|}
\hline Covariate & (1) & $(2)$ \\
\hline & Estimate & Estimate \\
\hline \multirow[t]{2}{*}{ TV avg. } & $0.158 * *$ & $0.157 * *$ \\
\hline & 0.009 & 0.009 \\
\hline \multirow[t]{2}{*}{2009} & $-0.166^{* *}$ & $-0.146^{* *}$ \\
\hline & 0.027 & 0.029 \\
\hline \multirow[t]{2}{*}{ TV avg*2009 } & $0.042 * *$ & $0.042 * *$ \\
\hline & 0.014 & 0.014 \\
\hline \multirow[t]{2}{*}{ ABC avg } & -0.006 & 0.001 \\
\hline & 0.008 & 0.01 \\
\hline \multirow[t]{2}{*}{ CBS avg } & 0 & -0.01 \\
\hline & 0.008 & 0.01 \\
\hline \multirow[t]{2}{*}{ NBC avg } & 0.005 & 0.001 \\
\hline & 0.008 & 0.009 \\
\hline \multirow[t]{2}{*}{ Fox avg } & 0.005 & 0.009 \\
\hline & 0.006 & 0.007 \\
\hline \multirow[t]{2}{*}{ A\&E avg } & $0.015 *$ & $0.023^{*}$ \\
\hline & 0.007 & 0.008 \\
\hline \multirow[t]{2}{*}{ Food avg } & 0.003 & 0.004 \\
\hline & 0.006 & 0.007 \\
\hline \multirow[t]{2}{*}{ PBS avg } & -0.012 & -0.007 \\
\hline & 0.007 & 0.008 \\
\hline \multirow[t]{2}{*}{ ComCentral avg } & 0.011 & 0.007 \\
\hline & 0.007 & 0.009 \\
\hline \multirow[t]{2}{*}{ USA avg } & $0.015^{*}$ & 0.007 \\
\hline & 0.006 & 0.007 \\
\hline \multirow[t]{2}{*}{ Starz avg } & -0.008 & -0.007 \\
\hline & 0.010 & 0.012 \\
\hline \multirow[t]{2}{*}{ Disney avg } & 0.008 & 0.015 \\
\hline & 0.008 & 0.010 \\
\hline \multirow[t]{2}{*}{ ABC avg*2009 } & -0.005 & -0.011 \\
\hline & 0.012 & 0.015 \\
\hline \multirow[t]{2}{*}{ CBS avg*2009 } & -0.015 & -0.01 \\
\hline & 0.012 & 0.015 \\
\hline \multirow[t]{2}{*}{ NBC avg*2009 } & 0.017 & 0.025 \\
\hline & 0.012 & 0.014 \\
\hline \multirow[t]{2}{*}{ Fox avg*2009 } & -0.007 & -0.014 \\
\hline & 0.01 & 0.011 \\
\hline \multirow[t]{2}{*}{ A\&E avg*2009 } & 0.006 & -0.006 \\
\hline & 0.011 & 0.012 \\
\hline \multirow[t]{2}{*}{ Food avg*2009 } & 0.003 & 0.008 \\
\hline & 0.01 & 0.012 \\
\hline PBS avg*2009 & -0.007 & 0 \\
\hline
\end{tabular}

\footnotetext{
${ }^{8}$ All regressions include fixed effects for DMA, a constant term, and demographic controls. Standard errors below each estimate are robust to arbitrary heteroskedasticity. + is significant at $10 \%, *$ is significant at $5 \%$, and $* *$ is significant at $1 \%$.
} 


\begin{tabular}{|c|c|c|}
\hline & 0.011 & 0.012 \\
\hline \multirow{2}{*}{ ComCentral avg*2009 } & -0.006 & $-0.026+$ \\
\hline & 0.011 & 0.014 \\
\hline \multirow[t]{2}{*}{ USA avg*2009 } & -0.003 & 0.004 \\
\hline & 0.01 & 0.012 \\
\hline \multirow[t]{2}{*}{ Starz avg*2009 } & $0.026+$ & $0.033+$ \\
\hline & 0.015 & 0.017 \\
\hline \multirow[t]{2}{*}{ Disney avg*2009 } & 0.007 & 0.004 \\
\hline & 0.012 & 0.015 \\
\hline \multirow[t]{2}{*}{ High risk } & & -0.005 \\
\hline & & 0.014 \\
\hline \multirow[t]{2}{*}{ High risk*2009 } & & -0.033 \\
\hline & & 0.022 \\
\hline \multirow[t]{2}{*}{ High risk*ABC avg } & & -0.017 \\
\hline & & 0.017 \\
\hline \multirow[t]{2}{*}{ High risk*CBS avg } & & 0.03 \\
\hline & & 0.017 \\
\hline \multirow[t]{2}{*}{ High risk*NBC avg } & & 0.012 \\
\hline & & 0.017 \\
\hline \multirow[t]{2}{*}{ High risk*Fox avg } & & -0.013 \\
\hline & & 0.014 \\
\hline \multirow{2}{*}{ High risk*A\&E avg } & & -0.027 \\
\hline & & 0.016 \\
\hline \multirow[t]{2}{*}{ High risk*Food avg } & & -0.003 \\
\hline & & 0.015 \\
\hline \multirow{2}{*}{ High risk*PBS avg } & & -0.017 \\
\hline & & 0.016 \\
\hline \multirow[t]{2}{*}{ High risk*ComCentral avg } & & 0.01 \\
\hline & & 0.015 \\
\hline \multirow[t]{2}{*}{ High risk*USA avg } & & 0.025 \\
\hline & & 0.014 \\
\hline \multirow[t]{2}{*}{ High risk*Starz avg } & & 0 \\
\hline & & 0.022 \\
\hline \multirow[t]{2}{*}{ High risk*Disney avg } & & -0.017 \\
\hline & & 0.017 \\
\hline \multirow[t]{2}{*}{ High risk*ABC avg*2009 } & & 0.015 \\
\hline & & 0.026 \\
\hline \multirow[t]{2}{*}{ High risk*CBS avg*2009 } & & -0.013 \\
\hline & & 0.026 \\
\hline \multirow{2}{*}{ High risk*NBC avg*2009 } & & -0.022 \\
\hline & & 0.026 \\
\hline \multirow[t]{2}{*}{ High risk*Fox avg*2009 } & & 0.023 \\
\hline & & 0.022 \\
\hline \multirow[t]{2}{*}{ High risk*A\&E avg*2009 } & & 0.042 \\
\hline & & 0.024 \\
\hline \multirow[t]{2}{*}{ High risk*Food avg*2009 } & & -0.014 \\
\hline & & 0.023 \\
\hline High risk*PBS avg*2009 & & -0.02 \\
\hline & & 0.025 \\
\hline
\end{tabular}




\begin{tabular}{|c|c|c|}
\hline High risk*ComCentral avg*2009 & & $0.051^{*}$ \\
\hline & & 0.024 \\
\hline High risk*USA avg*2009 & & -0.025 \\
\hline & & 0.023 \\
\hline High risk*Starz avg*2009 & & -0.025 \\
\hline High risk*Disney avg*2009 & & 0.033 \\
\hline & & 0.006 \\
\hline R-squared & 0.075 & 0.026 \\
\hline $\mathrm{N}$ & 59,738 & 0.076 \\
\hline
\end{tabular}


Table 4

The Role of Content in Cord Cutting using Alternative Content Preference Measure ${ }^{9}$

\begin{tabular}{|c|c|c|}
\hline Covariate & $\overline{(1)}$ & $\overline{(2)}$ \\
\hline & Estimate & Estimate \\
\hline \multirow[t]{2}{*}{ TV avg. } & $0.162 * *$ & $0.162 * *$ \\
\hline & 0.009 & 0.009 \\
\hline \multirow[t]{2}{*}{2009} & $-0.172 * *$ & $-0.158 * *$ \\
\hline & 0.027 & 0.029 \\
\hline \multirow[t]{2}{*}{ TV avg*2009 } & $0.039 * *$ & $0.039 * *$ \\
\hline & 0.014 & 0.014 \\
\hline \multirow[t]{2}{*}{ Broadcast avg } & 0.0003 & -0.011 \\
\hline & 0.007 & 0.008 \\
\hline \multirow[t]{2}{*}{ Non-broadcast avg } & $0.018 * *$ & 0.020 \\
\hline & 0.006 & 0.007 \\
\hline \multirow[t]{2}{*}{ Broadcast avg*2009 } & -0.007 & 0.002 \\
\hline & 0.010 & 0.012 \\
\hline \multirow[t]{2}{*}{ Non-broadcast avg*2009 } & 0.012 & 0.003 \\
\hline & 0.009 & 0.011 \\
\hline \multirow[t]{2}{*}{ High risk } & & -0.018 \\
\hline & & 0.014 \\
\hline \multirow[t]{2}{*}{ High risk*2009 } & & -0.019 \\
\hline & & 0.021 \\
\hline \multirow[t]{2}{*}{ High risk*Broadcast avg } & & $0.033^{*}$ \\
\hline & & 0.014 \\
\hline \multirow[t]{2}{*}{ High risk*Non-broadcast avg } & & -0.006 \\
\hline & & 0.013 \\
\hline \multirow[t]{2}{*}{ High risk*Broadcast avg*2009 } & & -0.026 \\
\hline & & 0.022 \\
\hline \multirow[t]{2}{*}{$\begin{array}{l}\text { High risk*Non-broadcast } \\
\text { avg*2009 }\end{array}$} & & 0.027 \\
\hline & & 0.020 \\
\hline R-squared & 0.075 & 0.075 \\
\hline $\mathrm{N}$ & 59,738 & 59,738 \\
\hline
\end{tabular}

\footnotetext{
${ }^{9}$ All regressions include fixed effects for DMA, a constant term, and demographic controls. Standard errors below each estimate are robust to arbitrary heteroskedasticity. + is significant at $10 \%$, * is significant at $5 \%$, and $* *$ is significant at $1 \%$.
} 